Article

\title{
Amphiphilic Block Copolymer Microspheres Derived from Castor Oil, Poly( $\varepsilon$-carpolactone), and Poly(ethylene glycol): Preparation, Characterization and Application in Naltrexone Drug Delivery
}

\author{
Maria Nerantzaki ${ }^{1,2, *}$, Eirini Skoufa ${ }^{3}$, Kyriakos-Vasileios Adam ${ }^{2}$, Stavroula Nanaki ${ }^{2}$, \\ Apostolos Avgeropoulos ${ }^{3} \mathbb{D}$, Margaritis Kostoglou ${ }^{4}$ and Dimitrios Bikiaris ${ }^{2, * \mathbb{D}}$ \\ 1 Physicochemistry Laboratory of Electrolytes and Interfacial Nanosystems (PHENIX), UMR CNRS 8234, \\ Faculty of Science and Engineering, Sorbonne University, 75252 Paris CEDEX 05, France \\ 2 Laboratory of Chemistry and Technology of Polymers and Dyes, Chemistry Department, Aristotle \\ University of Thessaloniki, 54124 Thessaloniki, Greece; kva.adam@gmail.com (K.-V.A.); \\ sgnanaki@chem.auth.gr (S.N.) \\ 3 Laboratory of Polymeric Materials, Department of Materials Science and Engineering, University of \\ Ioannina, Administration Building, University Campus Dourouti, 45110 Ioannina, Greece; \\ eiriniskoufa@gmail.com (E.S.); aavger@cc.uoi.gr (A.A.) \\ 4 Laboratory of General and Inorganic Chemical Technology, Aristotle University of Thessaloniki, \\ 54124 Thessaloniki, Greece; kostoglu@chem.auth.gr \\ * Correspondence: marinera002@msn.com (M.N.); dbic@chem.auth.gr (D.B.); Tel.: +30-23-1099-7812 (M.N.)
}

Received: 28 September 2018; Accepted: 12 October 2018; Published: 16 October 2018

Abstract: In the present study, the newly synthesized castor oil-derived thioether-containing $\omega$-hydroxyacid (TEHA) block copolymers with polycaprolactone (TEHA-b-PCL), with methoxypoly(ethylene glycol) (mPEG), (TEHA-b-mPEG) and with poly(ethylene glycol) (PEG) (TEHA-b-PEG-b-TEHA), were investigated as polymeric carriers for fabrication of naltrexone (NLX)-loaded microspheres by the single emulsion solvent evaporation technique. These microspheres are appropriate for the long-term treatment of opioid/alcohol dependence. Physical properties of the obtained microspheres were characterized in terms of size, morphology, drug loading capacity, and drug release. A scanning electron microscopy study revealed that the desired NLX-loaded uniform microspheres with a mean particle size of 5-10 $\mu \mathrm{m}$ were obtained in all cases. The maximum percentage encapsulation efficiency was found to be about $25.9 \%$ for the microspheres obtained from the TEHA-b-PEG-b-TEHA copolymer. Differential scanning calorimetry and X-ray diffractometry analysis confirmed the drug entrapment within microspheres in the amorphous state. In vitro dissolution studies revealed that all NLX-loaded formulations had a similar drug release profile: An initial burst release after $24 \mathrm{~h}$, followed by a sustained and slower drug release for up to 50 days. The analysis of the release kinetic data, which were fitted into the Korsmeyer-Peppas release model, indicated that diffusion is the main release mechanism of NLX from TEHA-b-PCL and TEHA-b-mPEG microspheres, while microspheres obtained from TEHA-b-PEG-b-TEHA exhibited a drug release closer to an erosion process.

Keywords: castor oil; poly(E-caprolactone); poly(ethylene glycol); amphiphilic block copolymers; microspheres; naltrexone; drug release

\section{Introduction}

Since the pioneering studies by Bader et al. in 1984 on the use of polymeric micelles in the form of microspheres for solubilizing anti-cancer drugs, amphiphilic copolymers, which can be 
either block copolymers (ABCs) or graft copolymers, have been used extensively in pharmaceutical applications ranging from sustained-release technologies to gene delivery [1]. The utility of ABCs for delivery of therapeutic agents results from their unique self-assembly property in aqueous media. Such copolymers are made up of two segments of different chemical nature, both hydrophilic and hydrophobic components [2]. The hydrophobic segment forms the core of the micelle, whereas the hydrophilic segment surrounds this core as a hydrated outer shell. This core-shell structure enables polymer microspheres, such as microspheres and nanoparticles, to have potential as vehicles for drug delivery because upon micellization, the hydrophobic core regions serve as reservoirs for hydrophobic drugs, which may be loaded by chemical, physical, or electrostatic means, depending on the specific functionalities of the core-forming block and the solubilizate [3].

Naltrexone (NLX) is a potent narcotic antagonist, which is used primarily in the continued management of alcohol dependence and opioid addiction [4,5]. Despite being a relatively effective and safe treatment, the clinical management of alcohol abuse/dependence by oral NLX can be compromised due to the patient's non-compliance with daily use of this medication. It was shown that $37 \%$ of patients discontinue daily oral NLX by 12 weeks and more than $80 \%$ discontinue use by 6 months [6]. Over the last few decades, an increasing body of research has suggested that the use of sustained release depot NLX preparations can overcome this issue [7]. Presently, there are two major sustained-release technologies for NLX release: Injectable intramuscular suspensions $\left(\right.$ Naltrel $^{\circledR}$, Vivitrol ${ }^{\circledR}$, and Depotrex ${ }^{\circledR}$ ), and surgically implantable pellets (Prodetoxone ${ }^{\circledR}$, Wedgewood ${ }^{\circledR}$, and $\mathrm{O}^{\prime} \mathrm{Nei}{ }^{\circledR}$ ) [8]. However, although the injectable sustained-release formulations address issues of daily oral NLX non-compliance, they still depend on patient compliance with treatment for subsequent treatments over 4 to 6 months. Subsequently, failure to return for subsequent treatment still remains a potential problem [9]. Concerning the sustained-release NLX implants, an early phase (up to 12 months post-implant) of inflammation, foreign body reaction, and fibrosis has been reported, while high cost of the implant limits its use [10].

Due to the aforementioned limitations, considerable interest has recently been shown in the design of new oral or parenteral sustained-release formulations of NLX (micelles, microspheres, and nanogels) $[7,8,11]$. Among these approaches, microparticulate drug delivery based on amphiphilic block copolymer microspheres (ABCs-based microspheres), has been gaining in importance. In this context, Akala et al. prepared and studied NLX-loaded poly(lactideco-glycolide) (PLGA) microspheres with the potential of sustained drug release from 30 to 150 days [12]. Additionally, Salehi et al. developed NLX-loaded thermoresponsive micelles based on poly(N-isopropylacrylamide)-b-poly(L-lactide) (PNIPAAm-b-PLA) with block ratios of 30/70 and $70 / 30$, capable of 5 and $18 \%$ of NLX release respectively, after $24 \mathrm{~h}$ [13]. The authors also suggested that in vitro release behavior could be tuned by varying the PNIPAAm to PLA ratio, since 30/70 and 70/30 formulations maintained high drug levels ( $45 \%$ and $10 \%$ of the initial NLX, respectively) over a period of 35 days of dissolution. Moreover, Pagar et al. employed a single emulsion solvent evaporation technique to obtain copolymer lactide-depsipeptide poly[LA-(Glc-Leu)] microspheres. In vitro release profile was characterized by an initial burst release of $49.3 \%$ from poly[LA-(Glc-Leu)] microspheres compared to $62.5 \%$ from polylactide (PLA) microspheres, while at the end of 30 days, about $80 \%$ of NLX was released [14]. To summarize, although the development of sustained release NLX products could significantly improve clinical outcomes for persons who suffer alcohol abuse/dependence, only a few micelle-based formulations have been created but suffer from instability and show very fast drug release behavior for sustained drug delivery have been proposed so far.

Consequently, despite the fact that ABCs-based microspheres seem to be a promising approach for the development of formulations with sustained NLX release ability, they need to be further stabilized. Microspheres made from conjugates of methoxypoly(ethylene glycol) (mPEG), poly(ethylene glycol) (PEG) and aliphatic polyesters such as polycaprolactone (PCL) are of particular interest because they can be useful in various controlled drug delivery applications, especially those involving relatively hydrophobic drugs [15]. We have previously reported some data on stable polymeric microspheres 
formed by amphiphilic triblock copolymers of PEG and poly(propylene succinate) (PPSu) with different hydrophobic/hydrophilic ratios [16]. Such microspheres can be useful in various controlled drug delivery applications, especially those involving poorly soluble drugs, including Tibolone, while they can exhibit different sizes, drug loading capacities, and drug release characteristics by varying the hydrophilic/hydrophobic ratio.

However, there might be several ways to still further enhance the drug delivery potential of ABCs-based microspheres. We have recently described the use of the castor-oil derivative TEHA, for the development of novel amphiphilic AB type (diblock) and ABA type (triblock) copolymers [17]. Such di/tri-block copolymers can be efficiently synthesized via the combination of a UV light-initiated thiol-ene "click" reaction and the following copolymerization of TEHA with $\varepsilon$-caprolactone ( $\varepsilon-C L)$, mPEG, or PEG. We also demonstrated that regardless of their block composition, the biorelavant yet biocompatible TEHA-based amphiphilic block copolymers are biocompatible, and therefore, they are very promising candidates for $\mathrm{ABCs}$-based microparticulate delivery.

Thus, the aim of this study was to explore the potential of castor-oil derived ABCs, to be used for the development of sustained-release drug delivery systems for NLX. For this purpose, microparticles containing NLX, were prepared using TEHA-based ABCs with different hydrophobic/hydrophilic compositions: TEHA-b-PCL, TEHA-b-mPEG, and TEHA-b-PEG-b-TEHA with an oil-in-water (O/W) emulsion/solvent evaporation technique. Afterwards, all the prepared formulations were subjected to physicochemical and pharmacokinetical studies to calculate several important properties such as molecular structure, crystalline structure, particle size and morphology, encapsulation efficiency, loading capacity, and drug release behavior.

\section{Materials and Methods}

\subsection{Materials}

Naltrexone drug, undecylenic acid (10-undecenoic acid) and mPEG 2000 were purchased from Fluka (Darmstand, Germany). $\quad \varepsilon$-CL $(98 \%), 2$ 2-mercaptoethanol (99\%), 2,2-dimethoxy2-phenylacetophenone (DMPA) (99\%), tin(II) 2-ethylhexanoate (Sn(Oct) 2 ) (95\%), PEG 1500, Poly(vinyl alcohol) (PVA), sodium chloride $(\mathrm{NaCl})$, and disodium hydrogen phosphate $\left(\mathrm{Na}_{2} \mathrm{HPO}_{4}\right)$ were supplied from Sigma-Aldrich Chemical Co. (Steinheim, Germany). Potassium dihydrogen phosphate $\left(\mathrm{KH}_{2} \mathrm{PO}_{4}\right)$ and dichloromethane (DCM, $\mathrm{CH}_{2} \mathrm{Cl}_{2} \geq 99.8 \%$ pure) was obtained from Chem-Lab and Merck Analytics (Kenilworth, NJ, USA), respectively. The stabilizer Tween 20 (Polysorbate 20) sorbitan monolaurate, were kindly supplied by Pharmathen S.A. (Athens, Greece). All the other reagents were of analytical grade and were used as received without further purification.

\subsection{Synthesis of TEHA, TEHA-b-PCL, TEHA-b-mPEG, and TEHA-b-PEG-b-TEHA}

TEHA was freshly prepared just prior to polymerization following a previously described UV light-initiated thiol-ene "click" reaction [18]. Briefly, a solution of undecylenic acid (15 g, $81 \mathrm{mmol})$ and 2-mercaptoethanol ( $6.36 \mathrm{~g}, 81 \mathrm{mmol})$ in $\mathrm{CH}_{2} \mathrm{Cl}_{2}$ was irradiated under $\mathrm{UV}$ light $(\lambda=365 \mathrm{~nm})$ in the presence of DMPA (2\% TEHA/initiator molar ratio) as a photoinitiator (Scheme 1i). A TEHA-b-PCL diblock copolymer was synthesized via ring-opening polymerization (ROP) of $\varepsilon$-CL using TEHA as a micro-initiator and $\mathrm{Sn}(\mathrm{Oct})_{2}$, as a catalyst (initiator/catalyst molar ratio 1:1), using a synthetic strategy that has been discussed in detail elsewhere [19]. In short, TEHA and $\varepsilon$-CL (in molar ratio 1:5) were mixed in a $100 \mathrm{~mL}$ round bottom flask connected to a vacuum. The mixture was degassed with a vacuum pump $(0.28 \mathrm{mbar})$ and kept at $150{ }^{\circ} \mathrm{C}$ for $1 \mathrm{~h}$, under nitrogen flow and constant stirring (350 rpm). The polymerization proceeded at $160^{\circ} \mathrm{C}$ for $6 \mathrm{~h}$ under increased mechanical stirring $(720$ $\mathrm{rpm})$ and a high vacuum $\left(10^{-3}-10^{-6}\right.$ Torr). When the polymerization was completed, the reaction product (TEHA-b-PCL) was cooled at an ambient temperature, and it was easily removed from the flask (Scheme 1ii). As previously reported, TEHA-b-mPEG diblock and TEHA-b-PEG-b-TEHA triblock copolymers were prepared through the two-stage melt polycondensation method [19]. Initially, TEHA 
and mPEG (molar ratio 1:0.04) or TEHA and PEG (molar ratio 1:0.05) were added to a nitrogen-purged round-bottom flask. Afterwards, the $\mathrm{Sn}(\mathrm{Oct})_{2}$-catalyzed (1\% TEHA/catalyst molar ratio) esterification reaction took place under $\mathrm{N}_{2}$ atmosphere and constant stirring at $150{ }^{\circ} \mathrm{C}$ for $1 \mathrm{~h}$. Finally, high vacuum $\left(10^{-3}-10^{-6}\right.$ Torr) was applied gradually and the polycondensation was carried out for $6 \mathrm{~h}$ under vigorous mechanical stirring (720 rpm) (Scheme 1iii,iv).

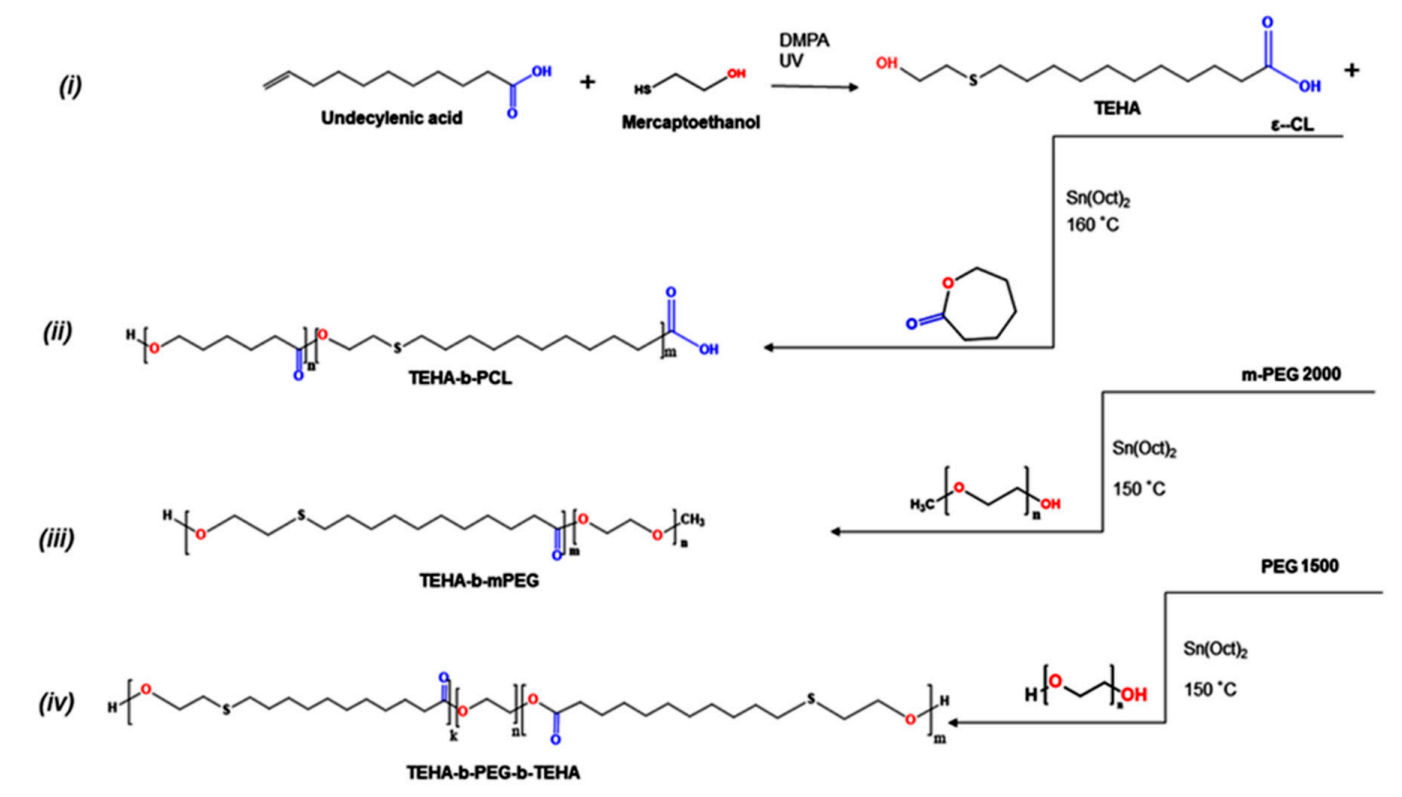

Scheme 1. (i) UV-irradiated synthesis of TEHA, (ii) synthesis of diblock copolymer TEHA-b-PCL via $\mathrm{ROP}$ of $\varepsilon$-CL, (iii) synthesis of diblock copolymer TEHA-b-mPEG, and (iv) of triblock copolymer TEHA-b-PEG-b-TEHA using a two-step melt polycondensation method.

\subsection{Preparation of TEHA- $b-P C L$, TEHA- $b-m P E G$, and TEHA-b-PEG- $b$-TEHA Microspheres}

An oil-in-water $(\mathrm{O} / \mathrm{W})$ emulsification and solvent evaporation technique was used for NLX microencapsulation in polyester matrices. In brief, $100 \mathrm{mg}$ of polymer and $10 \mathrm{mg}$ of NLX were dissolved in $5 \mathrm{~mL}$ of dichloromethane (DCM) and sonicated for $20 \mathrm{~min}$. Afterwards, the polymer-drug solution was added in $20 \mathrm{~mL}$ of $0.5 \mathrm{wt} \%$ PVA aqueous solution and the $\mathrm{O} / \mathrm{W}$ mixture was homogenized using a rotor stator stirrer (Ultra Turax IKA T18 basic, Staufen, Germany). The micronization lasted for $1 \mathrm{~min}$. Afterwards, the resulting emulsion formed was gently stirred until the evaporation of the organic solvent was completed. The microspheres were collected via centrifugation (3200 rpm for $15 \mathrm{~min}$ ), washed twice with de-ionised water, re-suspended into $5 \mathrm{~mL}$ of deionized water, frozen at $-4{ }^{\circ} \mathrm{C}$, and lyophilized at $-104^{\circ} \mathrm{C}$. Drug free microspheres were prepared similarly, without adding NLX.

\subsection{Characterization of Materials}

\subsubsection{Proton Nuclear Magnetic Resonance $\left({ }^{1} \mathrm{H}-\mathrm{NMR}\right)$ Spectroscopy}

${ }^{1} \mathrm{H}-\mathrm{NMR}$ spectra of copolymers were obtained using a Bruker spectrometer (Billerica, MA, USA) operating at a frequency of $400 \mathrm{MHz}$ for protons. Deuterated chloroform $\left(\mathrm{CDCl}_{3}\right)$ was used as a solvent and spectra were recorded at room temperature with tetramethylsilane (TMS) as an internal standard. The number of scans was 10 and the sweep width was $6 \mathrm{kHz}$.

\subsubsection{Size Exclusion Chromatography (SEC)}

A size exclusion chromatograph (SEC) (Polymer Laboratories, Shropshire, UK), equipped with an isocratic pump (SpectraSystem P1000, Thermo Fisher Scientific, San Jose, CA, USA), column oven (LabAlliance, Syracuse, NY, USA) heated to $35^{\circ} \mathrm{C}$ with three columns in series (PLgel $5 \mathrm{~mm}$ 
Mixed-C, 300u7.5 mm), refractive index (RI, Shodex RI-101, JM Science Inc., NY, USA), and ultraviolet absorbance (UV, SpectraSystem UV1000, Thermo Fisher Scientific, San Jose, CA, USA) detectors, and tetrahydrofuran (THF) as the eluent, was calibrated with eight polystyrene (PS) standards (Mp: 4.300 to $3.000 .000 \mathrm{~g} / \mathrm{mol}$ ). In every case, prior to calculating the polydispersity indices (PDI) of the unknown materials as well as prior to making an estimation on the average molecular weights (Mn and $\mathrm{Mw}$ ), a series of standard PS solutions were always tested in order to examine the accuracy of the measurements.

\subsubsection{X-ray Diffractometry (XRD)}

XRD analysis was performed on the microsphere formulations by scanning over the $5-30^{\circ} 2 \theta$ range, using a MiniFlex II diffractometer (Rigaku, model MiniFlex 600, Chalgrove, Oxford, UK) with $\operatorname{Bragg}$-Brentano geometry $(\theta, 2 \theta)$ and a Ni-filtered $\mathrm{Cu} K \alpha$ radiation $(\lambda=0.154 \mathrm{~nm})$.

\subsubsection{Fourier Transform-Infrared Spectroscopy (FTIR)}

FTIR spectra were obtained using a PerkinElmer FTIR spectrometer (Dresden, Germany), model Spectrum 1000. In order to collect the spectra, a small amount of freeze-dried microparticles was mixed with $\mathrm{KBr}$ (1 wt\% microparticles) and compressed to form tablets. The IR spectra of these tablets, in absorbance mode, were obtained in the spectral region of $450-4000 \mathrm{~cm}^{-1}$ using a resolution of $4 \mathrm{~cm}^{-1}$ and 64 co-added scans.

\subsubsection{Differential Scanning Calorimetry (DSC)}

A Perkin-Elmer, Pyris Diamond Differential Scanning Calorimeter (Dresden, Germany), calibrated with indium and zinc standards, was employed. A sample of about $10 \mathrm{mg}$ was placed in a scaled aluminum pan and heated from $30^{\circ} \mathrm{C}$ to $200^{\circ} \mathrm{C}$ at a heating rate of $10^{\circ} \mathrm{C} / \mathrm{min}$. The sample was held at that temperature for $5 \mathrm{~min}$ in order to erase any thermal history. The samples were cooled from the melt down to $30^{\circ} \mathrm{C}$ at a cooling rate of $10^{\circ} \mathrm{C} / \mathrm{min}$ and the subsequent heating scans from $30{ }^{\circ} \mathrm{C}$ to $200^{\circ} \mathrm{C}$ at a heating rate of $5{ }^{\circ} \mathrm{C} / \mathrm{min}$ were recorded.

\subsubsection{Scanning Electron Microscopy (SEM)}

The morphology of the prepared microspheres was studied using scanning electron microscopy (SEM) (JEOL JMS-840 apparatus, Tokyo, Japan). The samples were covered with a carbon coating in order to provide good conductivity of the electron beam. Operating conditions were: Accelerating voltage $20 \mathrm{kV}$, probe current $45 \mathrm{nA}$, and counting time $60 \mathrm{~s}$.

\subsubsection{Evaluation of Drug Encapsulation}

Quantitative analysis was performed using a Shimadzu high pressure liquid chromatography (HPLC, Shimadzu Scientific Instruments, Tokyo, Japan) prominence system consisting of a degasser (DGU-20A5, Tokyo, Japan), a liquid chromatograph (LC-20 AD, Shimadzu Scientific Instruments, Tokyo, Japan), an auto sampler (SIL-20AC, Shimadzu Scientific Instruments, Tokyo, Japan), a UV/Vis detector (SPD-20A, Shimadzu Scientific Instruments, Tokyo, Japan) and a column oven (Athena C18, Shimadzu Scientific Instruments, Tokyo, Japan). A modified previously validated method was used for the analysis [13]. In detail, a CNW Technology Athena C18, $(250 \mathrm{~mm} \times 4.6 \mathrm{~mm}$ and $5 \mu \mathrm{m}$ internal diameter) at column temperature of $40{ }^{\circ} \mathrm{C}$ chromatographic work station (CSW)was used for regression analysis and data acquisition. Concentration determination was performed using an HPLC-UV apparatus at $280 \mathrm{~nm}$ and was based on a previously created calibration curve. Flow rate was $1 \mathrm{~mL} / \mathrm{min}$ and the injection volume was $20 \mu \mathrm{L} / \mathrm{min}$. The calibration curve was created by diluting a stock aqueous solution of $400 \mathrm{ppm}$ naltrexone to concentrations $0.5,1,2.5,5,10,20,30$ and 50 ppm using the mobile phase: A $10 \mathrm{mM}$ phosphate buffer (pH was adjusted to 3.5 using $\mathrm{H}_{3} \mathrm{PO}_{4}$ ) with acetonitrile in a ratio of 80:20. Each sample was measured in triplicate. The percentage yield, 
drug loading, and drug entrapment efficiency of microspheres were calculated from the following equations, respectively:

$$
\begin{gathered}
\text { Yield of microspheres }(\%)=\frac{(\text { weight of microspheres })}{(\text { weight of polymer and drug fed initially })} \times 100 \\
\text { Drug loading }(\%)=\frac{(\text { weight of drug in microspheres })}{(\text { weight of microparticles })} \times 100 \\
\text { Entrapment efficiency }(\%)=\frac{(\text { weight of drug in microspheres })}{(\text { weight of initially used drug })} \times 100
\end{gathered}
$$

\subsubsection{In Vitro Release Profile}

NLX-loaded microspheres were sealed with cellulose dialysis membranes and were put in the sealed glass vials which were filled with $20 \mathrm{~mL}$ of $0.01 \mathrm{~mol} / \mathrm{L}$ phosphate buffer solution $(\mathrm{pH} 7.4)$ containing $0.02 \% \mathrm{NaN}_{3}$ and 0.04 polysorbate 20 (Tween 20). Three vials were set for each type of naltrexone microspheres. All the vials were incubated with horizontal oscillation (80 cycles $/ \mathrm{min})$ at $37^{\circ} \mathrm{C}$. Solutions were substituted completely with fresh ones at predetermined intervals. Substituted solutions at each time point were filtered through $0.45 \mu \mathrm{m}$ filter and sampled on the HPLC column.

\section{Results and Discussion}

\subsection{Synthesis and Characterization of Amphiphilic TEHA-Based Block Copolymers}

In this study, TEHA was synthesized following a previously described UV-induced thiol-Michael addition reaction, between 2-mercaptoethanol and 10-undecylenic acid (Scheme 1i). The completion of the thiol-ene reaction was confirmed by the absence of the vinylic and allylic hydrogen signals $[18,20]$ (around 5.00 and $2.00 \mathrm{ppm}$, respectively) in the ${ }^{1} \mathrm{H}-\mathrm{NMR}$ spectrum of TEHA (Figure 1). In addition to the total conversion of the double bonds, new ${ }^{1} \mathrm{H}$ chemical shifts of protons attached to the carboxylic and hydroxyl groups were detected in the spectrum of TEHA at $2.34 \mathrm{ppm}$ and $3.72 \mathrm{ppm}$, respectively (Figure $1, \mathrm{H}_{1}, \mathrm{H}_{4}$ ), while the methylene protons linked to sulfur appeared as two triple peaks at $2.73 \mathrm{ppm}$ and $2.51 \mathrm{ppm}$ (Figure $1, \mathrm{H}_{2}, \mathrm{H}_{3}$ ).

The ${ }^{1} \mathrm{H}-\mathrm{NMR}$ spectrum of the (AB type) diblock copolymer TEHA-b-PCL, which was synthesized via ROP of $\varepsilon$-CL using TEHA as a micro-initiator and $\mathrm{Sn}(\mathrm{Oct})_{2}$ as a catalyst, is displayed together with the spectrum of TEHA in Figure 1. As shown, TEHA-b-PCL has one multiple peak at $2.30 \mathrm{ppm}$ which corresponds to the $-\mathrm{CH}_{2} \mathrm{CO}$ - protons in PCL and TEHA units $\left(\mathrm{H}_{4,6}\right)$, and two triple peaks at 2.55 and $2.75 \mathrm{ppm}$, which can be assigned to the methylene protons linked to the sulfur atom $\left(-\mathrm{CH}_{2}-\mathrm{S}-\right)$ of TEHA block $\left(\mathrm{H}_{2}, \mathrm{H}_{3}\right)$ (Scheme 1ii). More importantly, in the spectrum of TEHA-b-PCL, the total conversion of the thioether functional groups was confirmed by the existence of shifts typical of $-\mathrm{CH}_{2}-\mathrm{OH}$ and $\mathrm{CH}_{2}-\mathrm{O}-$ proton signals at 4.20 and $4.05 \mathrm{ppm}$, respectively [17]. 

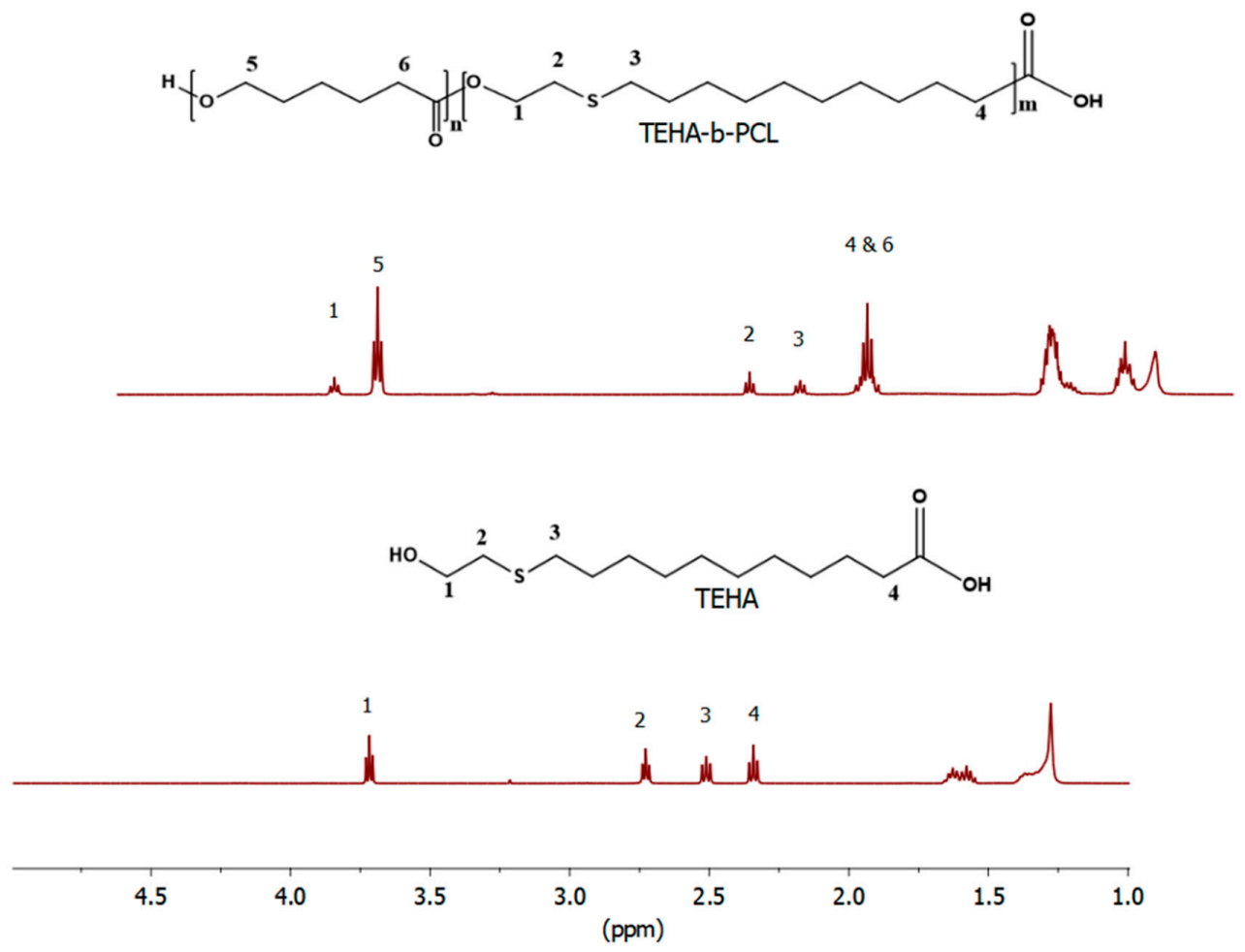

Figure 1. ${ }^{1} \mathrm{H}-\mathrm{NMR}$ spectra of TEHA and TEHA-b-PCL diblock copolymer.

To obtain the (AB type) di-block and (ABA type) tri-block copolymers TEHA-b-mPEG and TEHA-b-PEG-b-TEHA, a simple ester bond formation strategy between the carboxyl groups of TEHA and the hydroxyl groups of mPEG 2000 and PEG 1500 was used, as given in Scheme 1iii,iv. The structure and composition of the synthesized block copolymers was determined by ${ }^{1} \mathrm{H}-\mathrm{NMR}$ and the resulting spectra are presented in Figure 2, together with the spectrum of TEHA. For the diblock copolymer TEHA-b-mPEG, the methylene protons linked to sulfur $\left(-\mathrm{CH}_{2}-\mathrm{S}-\right)$ gave two triple peaks, which were observed at 2.55 and $2.75 \mathrm{ppm}$ and those linked to carbonyl group $\left(-\mathrm{CH}_{2} \mathrm{CO}-\right)$ and one triple peak at $2.20 \mathrm{ppm}$ (Figure 2, $\mathrm{H}_{2}, \mathrm{H}_{3}, \mathrm{H}_{4}$ ). Moreover, the signal of the protons linked to the hydroxyl group $\left(-\mathrm{CH}_{2}-\mathrm{OH}\right)$ was recorded at a higher chemical shift than for TEHA and appeared as a triple peak at $4.23 \mathrm{ppm}$ (Figure 2, $\mathrm{H}_{1}$ ). In addition to the higher chemical shift, the appearance of a new peak corresponding the methylene protons of methoxy group $\left(-\mathrm{CH}_{2} \mathrm{OCH}_{3}\right)$ at $3.65 \mathrm{ppm}$, further confirmed the successful synthesis of the TEHA-b-mPEG diblock copolymer (Figure 2, $\mathrm{H}_{5}$ ) [20].

Correspondingly, the ${ }^{1} \mathrm{H}-\mathrm{NMR}$ spectrum of TEHA-b-PEG-b-TEHA copolymer exhibited peak characteristics of both PEG and TEHA units. The signals assigned to the methylenes of $\left(-\mathrm{CH}_{2}-\mathrm{S}-\right)$ and $\left(-\mathrm{CH}_{2} \mathrm{CO}-\right.$ ) groups were recorded at $2.55 \mathrm{ppm}, 2.75 \mathrm{ppm}$ (Figure 2, $\mathrm{H}_{2}, \mathrm{H}_{3}$ ), and $2.30 \mathrm{ppm}$ (Figure 2, $\left.\mathrm{H}_{4}\right)$, respectively. In Figure 2, the signals corresponding to the $\left(-\mathrm{CH}_{2}-\mathrm{OH}\right)$ group come at a noticeably higher chemical shift than in TEHA and are found at $4.23 \mathrm{ppm}$, while those assigned to the methylene protons in methoxy group of PEG $\left(-\mathrm{CH}_{2} \mathrm{OCH}_{3}\right)$ appear as a new peak at $3.65 \mathrm{ppm}$, further supporting the fact that the TEHA-b-PEG-b-TEHA tri-block copolymer was successfully synthesized (Figure $2, \mathrm{H}_{1}, \mathrm{H}_{5}$ ).

SEC chromatography further confirmed the successful synthesis of TEHA-b-PCL, TEHA-b-mPEG, and TEHA-b-PEG-b-TEHA block copolymers since the corresponding SEC-traces, which are presented together with the traces of mPEG 2000 and PEG 1500 in Figure 3, showed a monomodal distribution [21]. More specifically, all the SEC traces of the block polymers were shifted to higher elution times, in comparison with the traces recorded for the initial mPEG 2000 and PEG 1500 monomers. 


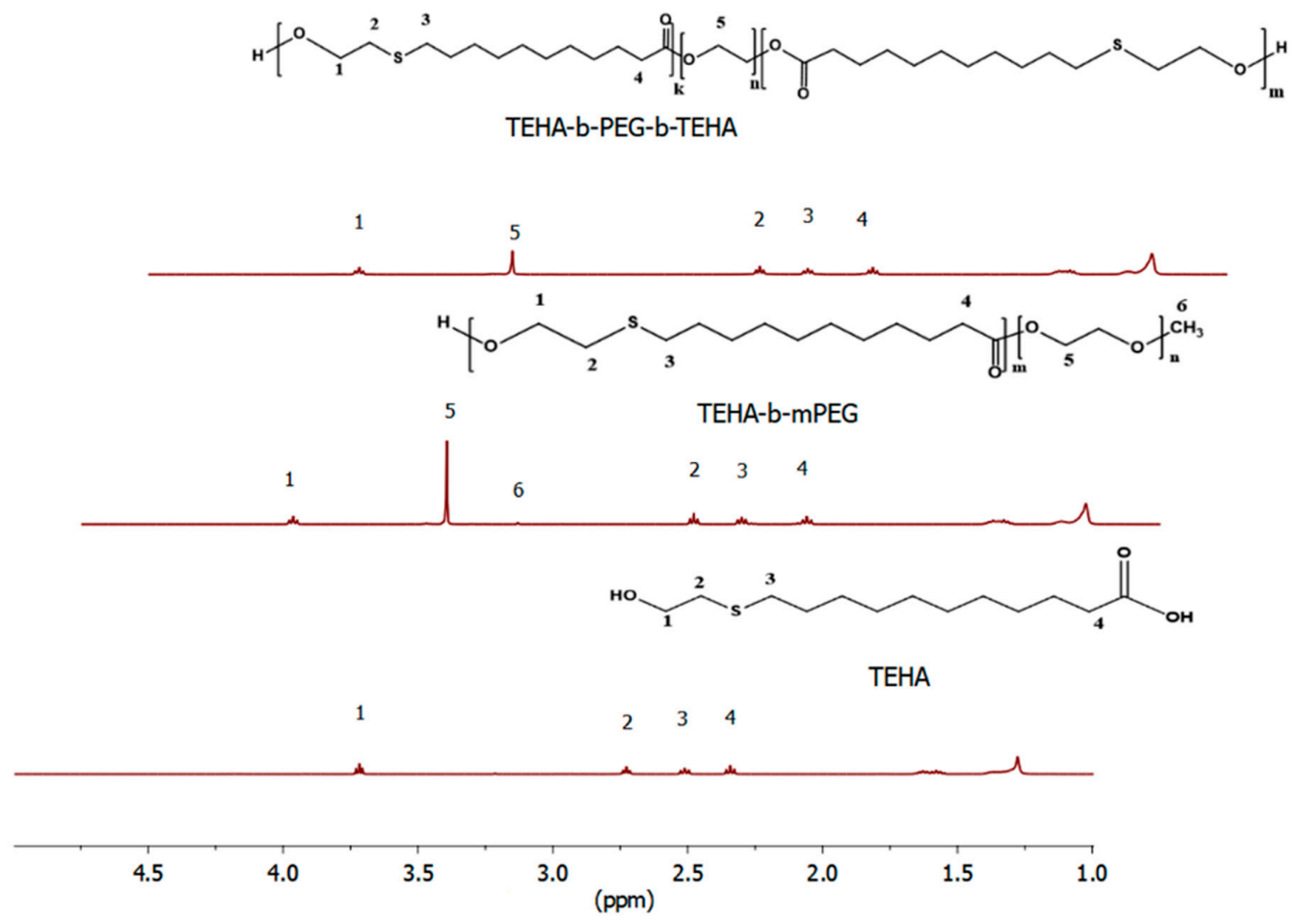

Figure 2. ${ }^{1}$ H-NMR spectra of TEHA, TEHA-b-mPEG diblock, and TEHA-b-PEG-b-TEHA triblock copolymers.

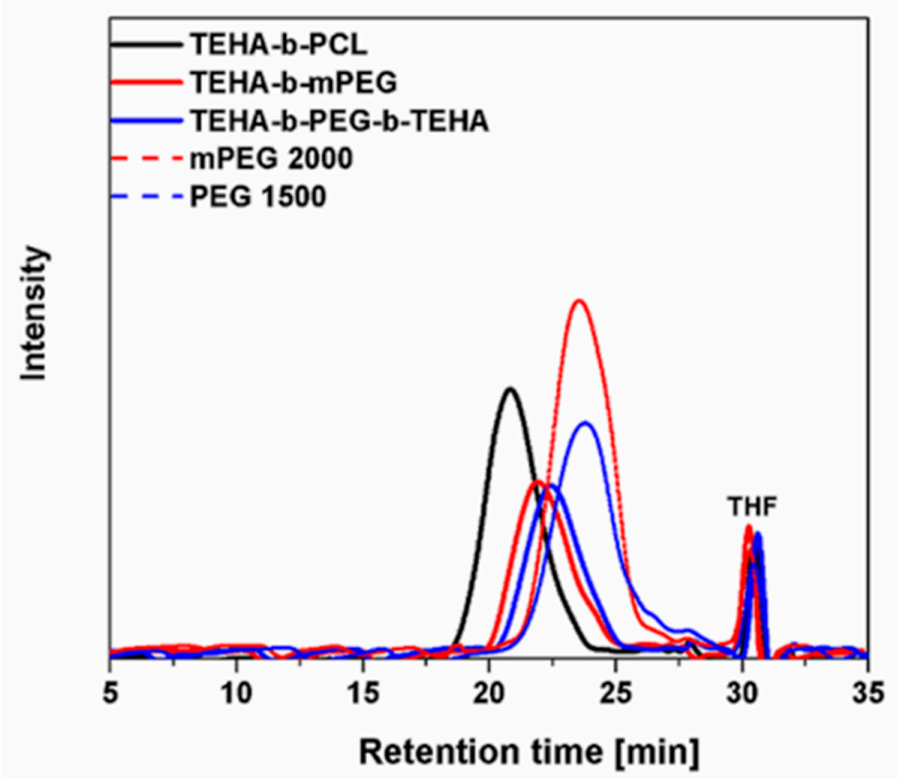

Figure 3. SEC traces of TEHA-b-PCL, TEHA-b-mPEG, and TEHA-b-PEG-b-TEHA block copolymers, compared to the peaks obtained for mPEG 2000 and PEG 1500.

Table 1 shows the molecular weights and polydispersity indices (PDI) of the TEHA-based block copolymers. The calculated number-based average molecular weights (Mn) of TEHA-b-PCL, TEHA-b-mPEG, and TEHA-b-PEG-b-TEHA were in good accordance with the initial feed ratios and were found to be $9800 \mathrm{~g} / \mathrm{mol}, 4800 \mathrm{~g} / \mathrm{mol}$, and $2.500 \mathrm{~g} / \mathrm{mol}$ respectively. In addition, small polydispersity index (PDI) values close to 1 were detected. These results indicated that no transesterification and/or backbiting reactions occurred during the copolymerization [22]. 
Table 1. Molecular characteristics of TEHA-b-PCL, TEHA-b-mPEG, and TEHA-b-PEG-b-TEHA block copolymers.

\begin{tabular}{ccccc}
\hline Sample & Feed Molar Ratio $^{\mathbf{1}}$ & $\mathbf{M n}^{\mathbf{2}} \mathbf{( g / \mathbf { m o l } )}$ & $\mathbf{M w}^{\mathbf{2}} \mathbf{( g / m o l )}$ & PDI $^{\mathbf{2}}$ \\
\hline TEHA-b-PCL & TEHA:E-CL, $1: 5$ & 9800 & 14.800 & 1.55 \\
THEA-b-mPEG & TEHA:mPEG, 1:0.05 & 4.800 & 6.700 & 1.40 \\
TEHA-b-PEG-b-TEHA & TEHA:PEG, 1:0.04 & 2.500 & 3.675 & 1.47 \\
\hline
\end{tabular}

${ }^{1}$ Hydrophylic/hydrophobic block ratio. ${ }^{2}$ Determined using SEC with THF as the eluent and polystyrene as standards.

\subsection{Evaluation of Drug-Loaded Microspheres Prepared from Amphiphilic TEHA-Based Block Polymers}

\subsubsection{Drug Loading and Morphology of Prepared Microspheres}

In the present study, NLX-loaded microspheres were prepared by using the $\mathrm{O} / \mathrm{W}$ solvent evaporation method. This method was selected because the drug and the polymers were soluble in DCM. The percentage yields, drug loading capacity (DL), and entrapment efficiencies (EE) for NLX-loaded microspheres prepared from the amphiphilic copolymers TEHA-b-PCL, TEHA-b-mPEG, and TEHA-b-PEG-b-TEHA are shown in Table 2. The maximum percentage EE was found to be $25.9 \%$ for the microspheres obtained from copolymer TEHA-b-PEG-b-TEHA, which also had the highest yield and drug loading compared to the other copolymers. TEHA-b-PCL also showed a high DL percentage and yield of $1.19 \% \pm 0.6 \%$ and $41.5 \% \pm 2 \%$, respectively. This low drug loading was expected due to the high hydrophobicity of the NLX drug $[15,22]$.

Table 2. Percentage yield, drug loading and encapsulation efficiency of prepared microspheres.

\begin{tabular}{cccc}
\hline Sample & Yield (\%) & Drug Loading (\%) & Encapsulation Efficiency (\%) \\
\hline NLX-loaded/TEHA-b-PCL & $41.5 \pm 2.1$ & $1.19 \pm 0.6$ & $25.6 \pm 1.5$ \\
NLX-loaded/THEA-b-mPEG & $32.3 \pm 3.2$ & $0.27 \pm 0.07$ & $7.6 \pm 0.9$ \\
NLX-loaded/TEHA-b-PEG-b-TEHA & $89.9 \pm 5.2$ & $2.71 \pm 0.5$ & $25.9 \pm 1.4$ \\
\hline
\end{tabular}

In general, several parameters, such as nature of the hydrophilic (corona) and hydrophobic (core) forming block, the length of the core, and total copolymer molecular weight are some parameters affecting the DL, as well as the nature and length of the corona forming block [23,24]. For a block copolymer drug delivery vehicle system with a constant length of the hydrophilic segment, it was expected that an increase in the length of core forming block raised the partition coefficient for the solubilizate [25]. Therefore, it is suggested here that the copolymers with longer hydrophobic chains self-assembled into micelles in the form of microspheres with a more compact inner core, reducing the aggregation possibility of drug-loaded microspheres and improving the DL through increasing the hydrophobic interaction between the drug and the copolymer [26].

The morphology of the prepared microspheres was another determining factor of drug vehicle efficacy and thereby parameters affecting the micelle size are required to be revealed in order to prepare long circulating microparticulate drug carriers [27]. In this study, SEM was used to determine the size, shape, and surface morphology of the NLX-loaded microspheres. As shown in Figure 4, well-defined NLX-loaded microspheres with a uniform spherical shape were prepared by using a simple $\mathrm{O} / \mathrm{W}$ emulsion technique. More particularly, in Figure $4 a-d$ it can be seen that NLX-loaded microspheres prepared using TEHA-b-PCL and TEHA-b-mPEG were spherical in form, mostly having smooth surfaces, while NLX-loaded microspheres prepared uisng TEHA-b-PEG-b-TEHA had a spherical shape and comparatively rough surfaces (Figure 4e,f).

Another crucial property that should be considered while preparing drug delivery vehicles is the size of microspheres. Those microspheres that are smaller than $200 \mathrm{~nm}$ in size are less susceptible to rapid removal from the circulatory blood stream by the reticuloendothelial system and those smaller than $5 \mu \mathrm{m}$ are able to enter small capillaries [28]. SEM images in Figure 4 indicate that desired 
NLX-loaded spherical microspheres with a mean particle size of 5-10 $\mu \mathrm{m}$ were obtained at a stirring speed of $3200 \mathrm{rpm}$; no clear differences were seen between the different used copolymers. Generally, the smaller the mean particle size, the shorter the diffusion path for drug release, and thus, the faster the release rate and vice versa. Consequently, controlling the particle size provides a means of tuning drug release profiles [29].
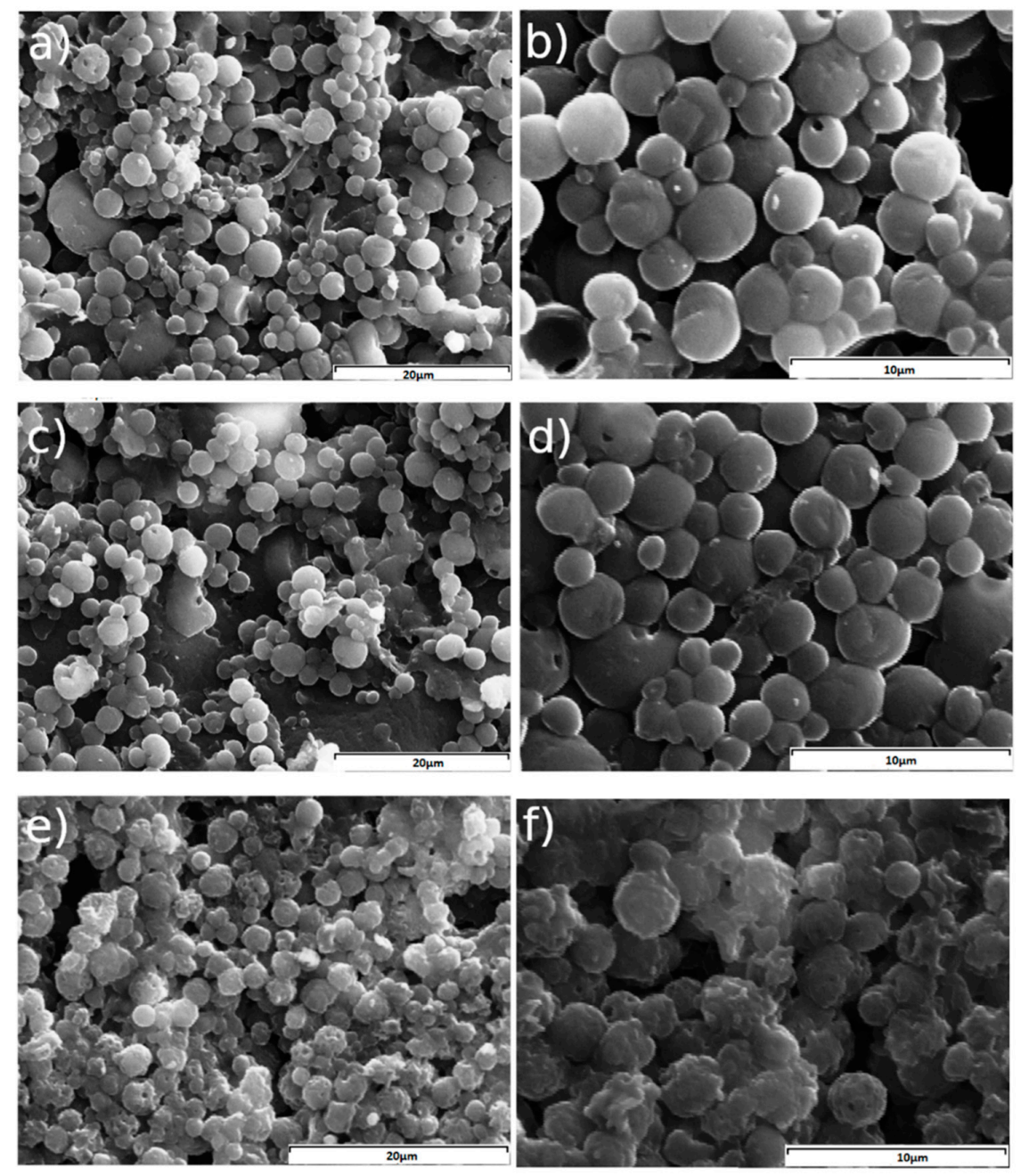

Figure 4. SEM images of $(\mathbf{a}, \mathbf{b})$ NLX-loaded/TEHA-b-PCL, $(\mathbf{c}, \mathbf{d})$ NLX-loaded TEHA-b-mPEG, and (e,f) NLX-loaded/TEHA-b-PEG-b-TEHA microspheres at low (left) and high (right) magnification.

\subsubsection{FTIR, XRD and DSC Analysis of Microparticles}

Figure 5 depicts the FTIR spectra of NLX in comparison with drug-free and drug-loaded microspheres prepared from the amphiphilic TEHA-based polymers TEHA-b-PCL, TEHA-b-mPEG, and TEHA-b-PEG-b-TEHA. The FTIR spectra of NLX presents absorption bands at 3000-3100, 1655, 1558 , and $1457 \mathrm{~cm}^{-1}$ assigned to the benzene rings, at $1456 \mathrm{~cm}^{-1}$ and $1100 \mathrm{~cm}^{-1}$ due to $C-C$ stretching bands and C-O respectively, a strong peak at $1765 \mathrm{~cm}^{-1}$ due to its $>\mathrm{C}=\mathrm{O}$ group, and a broad peak at $3450 \mathrm{~cm}^{-1}$ due to the existence of $-\mathrm{OH}$ groups [30]. The FTIR spectra of all NLX-free microspheres showed the characteristic peaks commonly found in the polymer chain backbone: A broad band at $3600-3300 \mathrm{~cm}^{-1}$, which was assigned to $\mathrm{O}-\mathrm{H}$ stretching, the stretching vibration band of $\mathrm{C}=\mathrm{O}$ at $1700-1680 \mathrm{~cm}^{-1}$, and the $\mathrm{C}-\mathrm{H}$ stretching vibration peak at $3000-2900 \mathrm{~cm}^{-1}$ [31]. Moreover, the ester vibrations showed characteristic peaks at $1268-1020 \mathrm{~cm}^{-1}$. The FTIR spectra for NLX-loaded microspheres were almost identical to the spectra obtained for NLX-free microspheres, as shown in Figure 5, suggesting the absence of a chemical interaction between drug and copolymers. 
XRD analysis was used to study the crystal structure of the drug in the formed microspheres. NLX showed the characteristic intense peaks at $2 \theta 21.6^{\circ}$ and $24^{\circ}$ due to its crystalline nature [32]. However, in XRD curves for NLX-loaded/TEHA-b-PCL MS and NLX-loaded/TEHA-b-mPEG MS, presented in Figure $6 \mathrm{a}, \mathrm{b}$, could not be observed because they overlapped with the peaks assigned to the polymer chains of TEHA-b-PCL $\left(2 \theta 22.1^{\circ}\right.$ and $\left.24.3^{\circ}\right)$ and TEHA-b-mPEG $\left(2 \theta 21.7^{\circ}\right.$ and $\left.23.5^{\circ}\right)$. In the case of NLX-loaded/TEHA-b-PEG-b-TEHA MS (Figure 6c), the sharp peak of TEHA-b-PEG-b-TEHA was recorded at $2 \theta 21.5^{\circ}$, while a weak peak corresponding to NLX appeared at $2 \theta 21.5^{\circ}$, suggesting that the crystalline state of NLX was reduced or NTX was in its amorphous state. This decrease in crystallinity was probably due to the inhibition effect of the copolymer on the drug crystallization procedure [33]. It is worth mentioning that for all NLX-loaded MS, the signals assigned to TEHA-b-PCL, TEHA-b-mPEG, and TEHA-b-PEG-b-TEHA copolymer chains were weak compared with the blank microsphere. This result indicates that the crystalline state of the copolymers was also reduced during the drug encapsulation process [34].
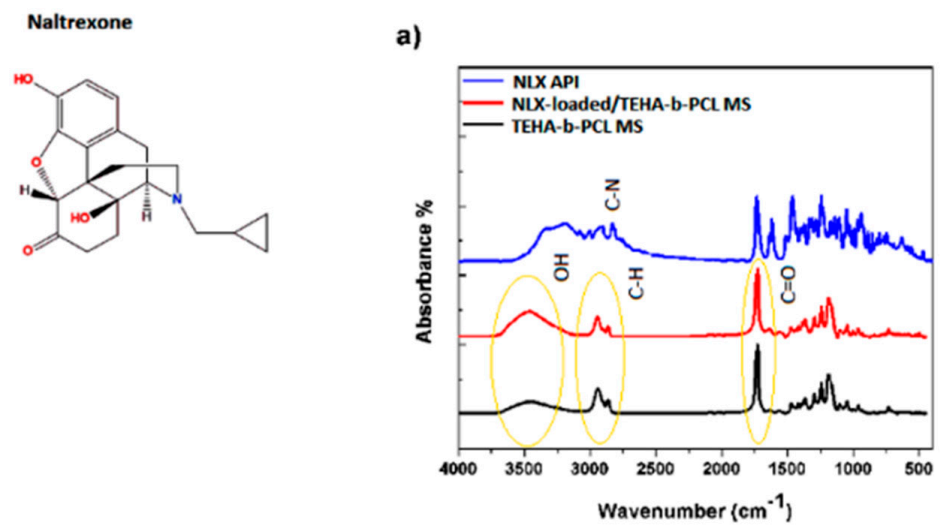

b)

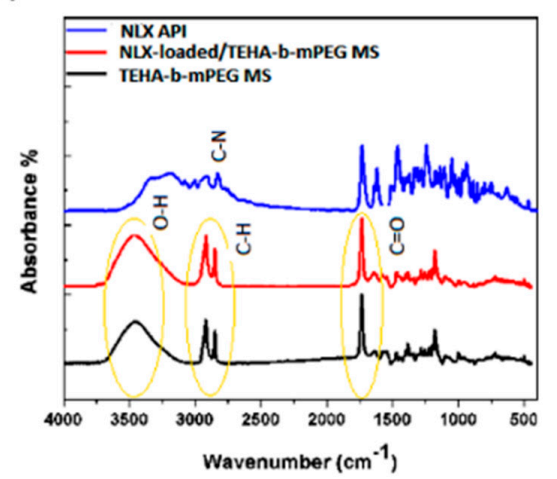

c)

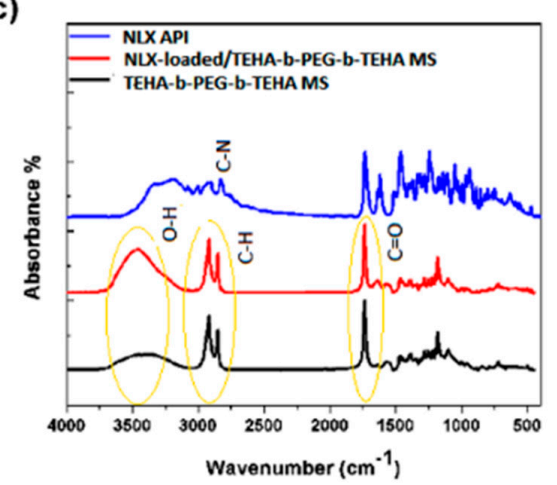

Figure 5. FTIR spectra of NLX in comparison with drug-free and drug loaded microspheres prepared from amphiphilic TEHA-based polymers: (a) TEHA-b-PCL; (b) TEHA-b-mPEG and (c) TEHA-b-PEG-b-TEHA. 
a)

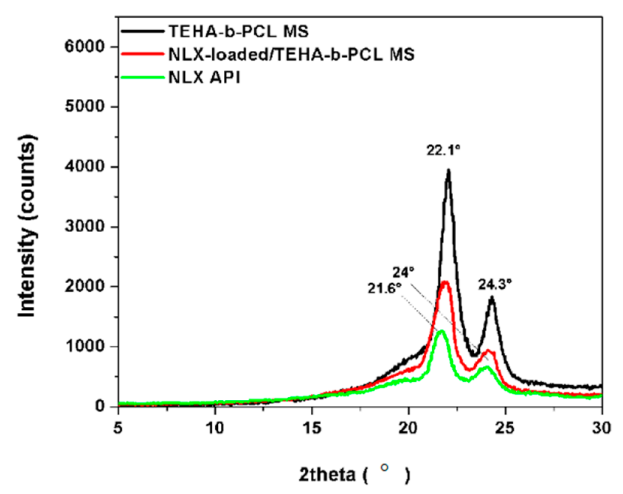

b)

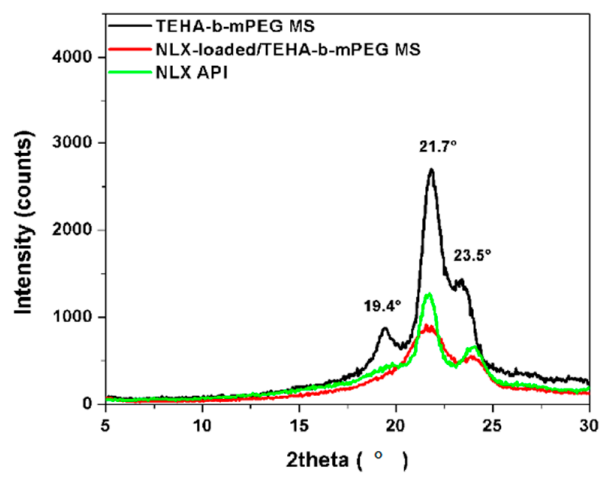

c)

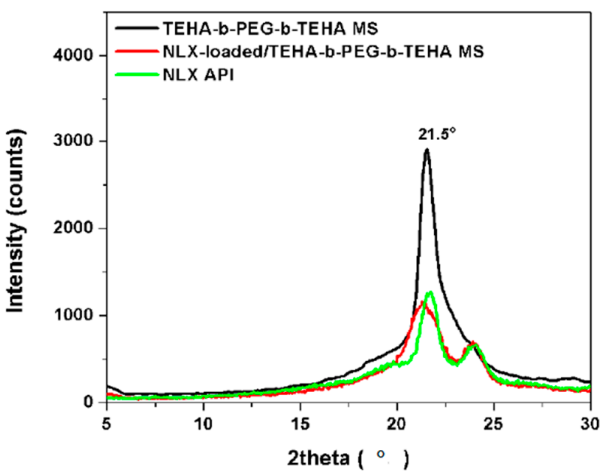

Figure 6. XRD patterns of NLX API in comparison with NLX-free and NLX-loaded microspheres prepared from amphiphilic TEHA-based copolymers: (a) TEHA-b-PCL, (b) TEHA-b-mPEG, and (c) TEHA-b-PEG-b-TEHA.

DSC curves of NLX and NLX-loaded TEHA-b-PCL, TEHA-b-mPEG, and TEHA-b-PEG-b -microspheres are shown in Figure 7. NLX showed an endothermic peak near $177{ }^{\circ} \mathrm{C}$ due to its melting point [32], while for the NLX-loaded microspheres, endothermic peaks were not recorded, suggesting that the drug was encapsulated in the amorphous state and that it was distributed in the polymer matrix. In agreement with results of previous DSC studies [17], the endothermic peaks of TEHA-b-PCL, TEHA-b-mPEG and TEHA-b-PEG-b-TEHA were recorded at 51.5, 48.2-67.1 (double peak) and $54.7-73.7^{\circ} \mathrm{C}$ (double peak), respectively. 


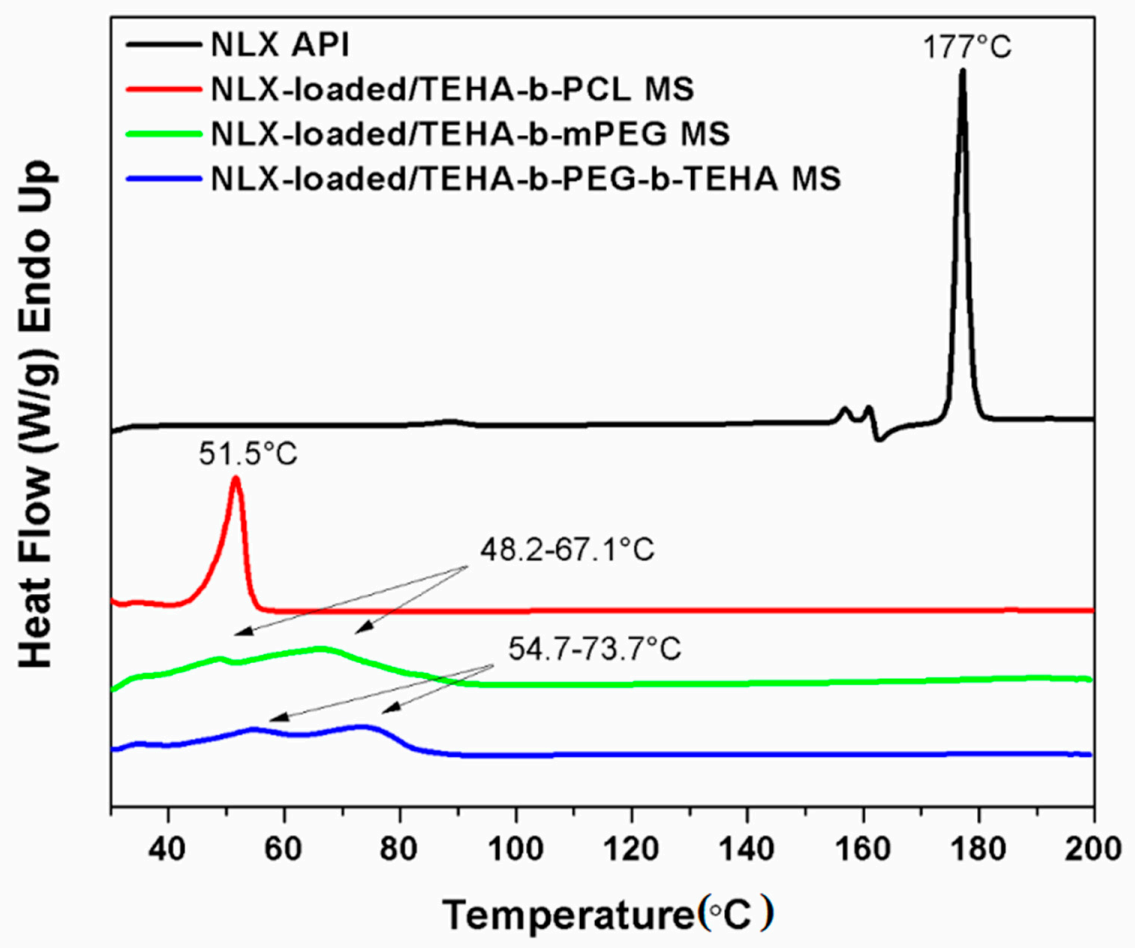

Figure 7. DSC thermograms of NLX API, NLX-loaded TEHA-b-PCL, NLX-loaded/TEHA-b-mPEG, and NLX-loaded TEHA-b-PEG-b-TEHA microspheres.

\subsubsection{In Vitro Release Properties}

Release of drug molecules from the micellar vehicle is as important as loading of the microspheres. The release rate can be considered as diffusion and affected from the micelle stability and biodegradability of the copolymer micelle [35]. If the micelle is stable enough and biodegradability rate is low, the release rate of drug molecules from the micelle core is influenced by many factors such as the strength of the interaction between the core forming block and drug molecules, the physical state of the micelle core, the amount of drug molecules loaded, the molecular volume of drug molecules, and the length of the core forming block and the localization of drug molecules within the micelle [36]. Most of these factors also affect the loading capacity of the micelle and could have a reverse effect on it. For this reason, the optimum value for these factors should be figured out while designing a new drug delivery vehicle [37].

In this study, the in vitro release behavior of micelle-encapsulated NLX in phosphate buffered saline (PBS) ( $\mathrm{pH} 7.4)$ at $37^{\circ} \mathrm{C}$ was studied using a dialysis method, and the results are shown in Figure 8 . The in vitro drug release study indicated that the molecular characteristics of di/triblock copolymers used in this study, affected the release rate of drug from microspheres. More specifically, TEHA-b-PCL and TEHA-b-mPEG micelle-encapsulated NLX was observed to be rapidly released and reached its peak of $80 \%$ and $89 \%$ of the total in the first $24 \mathrm{~h}$. In comparison, for TEHA-b-PEG-b-TEHA micelle-encapsulated NLX, the burst effect was less and about $55 \%$ of NLX was released in $72 \mathrm{~h}$. A three-step drug release profile is shown in Figure $8 \mathrm{~b}$. A large initial burst release occurred within the first 5 days, followed by a long period of matrix-diffusion kinetics, and then a very slow release rate. NLX loaded in TEHA-b-PEG-b-TEHA copolymer showed a lower burst release compared with the other two copolymers, and there was a sustained release up until 50 days. The higher release rate of NLX from TEHA-b-PCL microspheres should be attributed to the lower melting point that this copolymer has. This was proved in our previous studies in aliphatic polyesters and copolymers [38,39]. A melting point of an aliphatic polyester close to body temperatures gives the highest rates. This also explains the lowest release rate of NLX from the TEHA-b-PEG-b-TEHA copolymer, which according to recorded DSC thermographs, has the highest melting point from all copolymers. 
a)

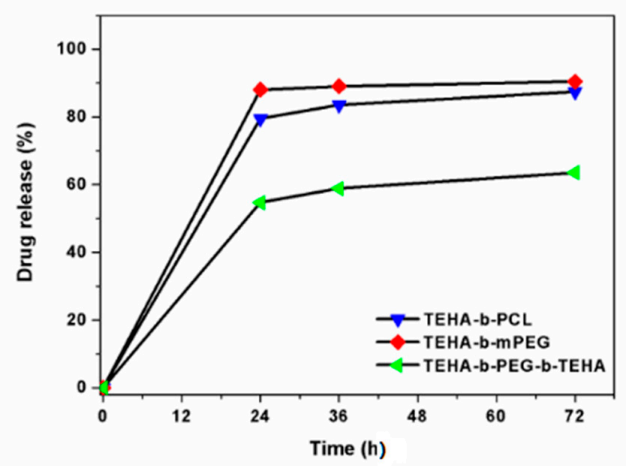

b)

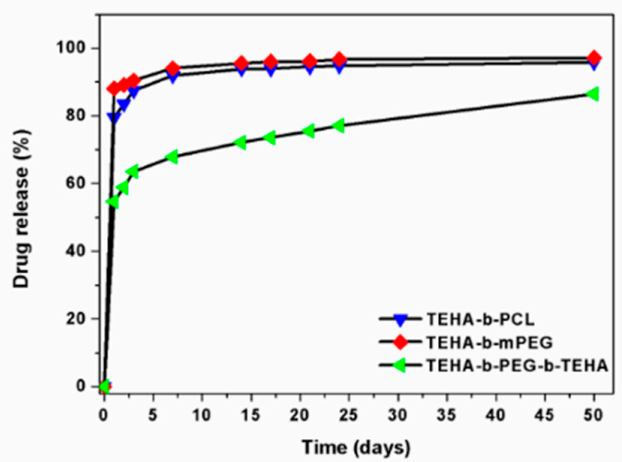

Figure 8. Percentage of release of NLX from microspheres prepared from amphiphilic TEHA-based copolymers at different time intervals: (a) 24, 48 and 72 h, and (b) 1, 2, 3, 7, 14, 17, 21, 24 and 50 days.

The in vitro release results indicated that NLX could be slowly released from microspheres in a sustained manner in vitro. The sustained release of NLX from the microspheres might be due to two reasons: (1) The diffusion of NLX from the microspheres to the medium, and (2) Degradation and hydrolysis of microspheres induced release of NLX to the medium. Figure 9 presents the morphology of the microspheres after 50 days of dissolution. It is clear there the surface of all microspheres have been changed after drug dissolution, and in all cases, the surface became rough and the regular spherical shape that was observed in initial microspheres has been lost. Furthermore, the internal morphology in TEHA-b-PEG-b-TEHA confirms the presence of cavities, which shows that the drug passed from the polymer matrix into the external environment and some erosion also took place. Therefore, it seems that diffusion was the main mechanism for TEHA-b-PCL and TEHA-b-mPEG copolymers while diffusion and erosion could be the release mechanism for NLX from TEHA-b-PEG-b-TEHA copolymers [40].
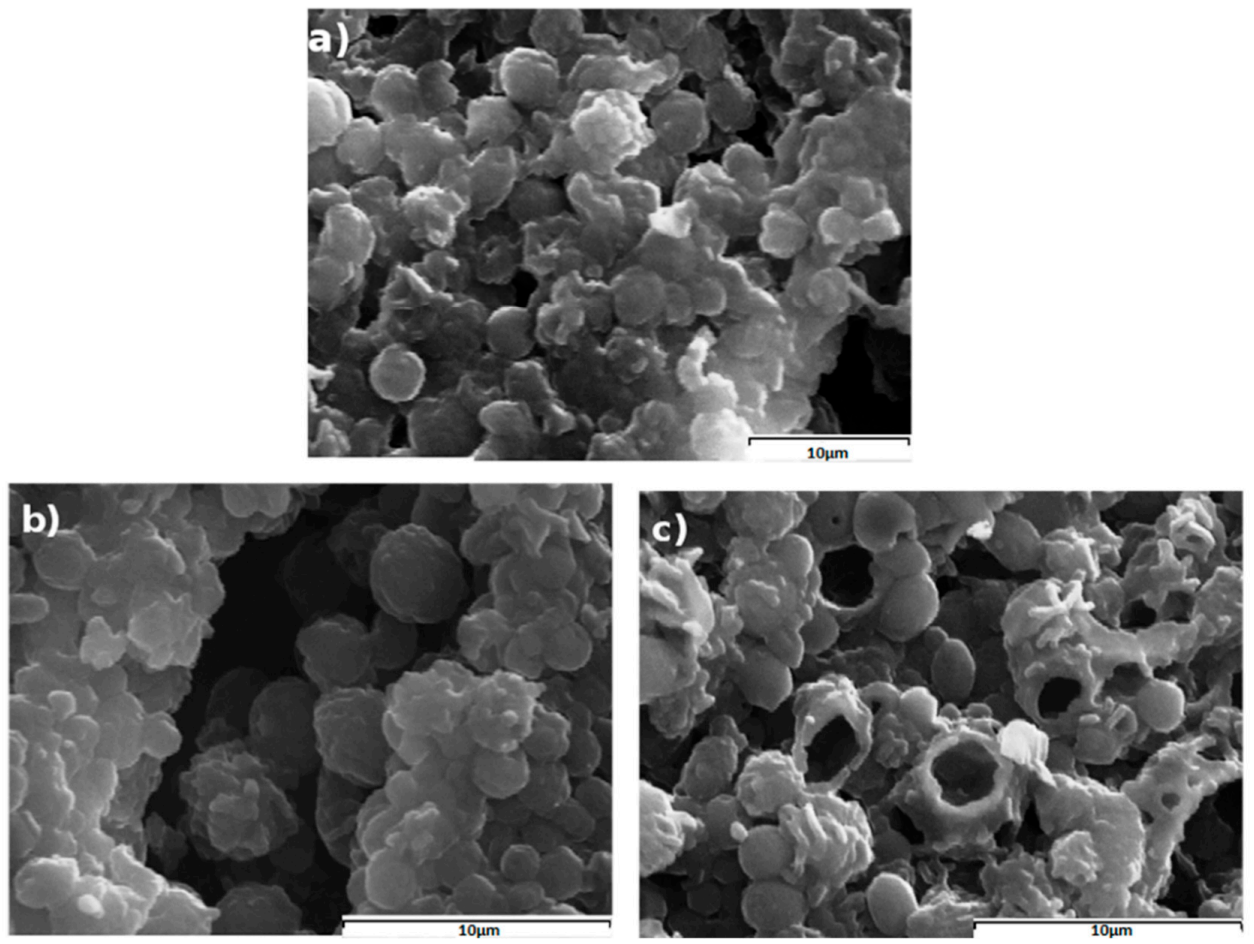

Figure 9. SEM images of (a) NLX-loaded/TEHA-b-PCL; (b) NLX-loaded TEHA-b-mPEG; (c) NLX-loaded/TEHA-b-PEG-b-TEHA microspheres after 50 days of dissolution. 


\subsubsection{Drug Release Kinetics}

In the present section the drug release kinetics data will be analyzed based on the corresponding theories. The scope of such an analysis is two-fold: At first to create a mathematical model for the process and second to extract information on the structure of the drug-particle system. In general, the drug release from polymeric matrices can be due to two different physical processes: (i) Diffusion of the drug in the polymer matrix and (ii) Polymer erosion leading to the release of the drug located at the eroded polymer portion. The intense mixing in the present experiments ensured that the resistance to mass transfer of drugs from the polymer surface to the bulk liquid could be neglected. The experimental kinetics data are restricted to the region of completion (high total release) so the Peppas-Korsmayer generalized diffusion model, which can be applied for release up to $60 \%$, cannot be used here [41]. As it has been already discussed in a previous section, the dominant release mechanism for copolymers TEHA-b-PCL and TEHA-b-mPEG appears to be diffusion. Let us first consider the diblock copolymer TEHA-b-PCL. The first order kinetics model, which is an approximation of the linear (Fickian) diffusion mechanism, was tested as a starting point. The fitting process led to failure since the matching to the first data point corresponded to a release process ending at 3 days. The next step was to consider the exact solution for Fickian diffusion in spherical coordinates (since the polymer particles had an approximately spherical shape). This solution has the form [42]:

$$
\mathrm{M}=\mathrm{M}_{\mathrm{o}}\left(1-\frac{6}{\pi^{2}} \sum_{\mathrm{i}=1}^{\infty} \frac{1}{\mathrm{i}^{2}} \exp \left(-\mathrm{Di}^{2} \pi^{2} \mathrm{t} / \mathrm{R}^{2}\right)\right)
$$

where $\mathrm{M}$ is the released fraction, $\mathrm{M}_{\mathrm{o}}$ is the final released fraction, $\mathrm{t}$ is time (in days), $\mathrm{R}$ is the spherical particle radius, and $\mathrm{D}$ is the diffusion coefficient of the drug in the polymer matrix. The fitting procedure did not improve the situation met by the first order kinetic model. Therefore, a simple diffusion process could not describe the experimental data. There are several possible explanations for this behavior. The most straightforward are the non-uniform distribution of drugs in the particles and/or the existence of several regions in the particles with different diffusion coefficients. In the absence of additional information, the second scenario is employed here since it admits much easier manipulation. By considering the deviation between the diffusion model and the data, it was found that a simple exponential may be used to fill the gap. This corresponds to a fraction of the drug that diffused with a different diffusion coefficient. The model equation in this scenario is:

$$
\mathrm{M}=\mathrm{M}_{1}\left(1-\frac{6}{\pi^{2}} \sum_{\mathrm{i}=1}^{\infty} \frac{1}{\mathrm{i}^{2}} \exp \left(-\mathrm{D}_{1} \mathrm{i}^{2} \pi^{2} \mathrm{t} / \mathrm{R}^{2}\right)\right)+\mathrm{U}(\mathrm{t}-1) \mathrm{M}_{2}(1-\exp (-\mathrm{A}(\mathrm{t}-1)))
$$

where $M_{1}$ and $M_{2}$ are the fractions of total drug having diffusion coefficients $D_{1}$ and $D_{2}$, respectively. The fitting coefficient $\mathrm{A}$ is related to the diffusivity $\mathrm{D}_{2}$ through the so-called linear driving force formula: $A=15 D_{2} / R^{2}$ [43]. The function $U$ is the so-called step function taking the values zero and one for negative and positive arguments, respectively. The fact that the second diffusion process started at $\mathrm{t}=1$ implies that there was a lack of this type of drug in the external regions of the particles. Assuming a (volume) average particle radius of $2 \mu \mathrm{m}$ as resulted from the SEM pictures, and successfully fitting Equation (5) to the experimental data, leads to the following parameter values: $\mathrm{M}_{1}=0.83, \mathrm{M}_{2}=0.13, \mathrm{D}_{1}=1.4 \times 10^{-17} \mathrm{~m}^{2} / \mathrm{s}$, and $\mathrm{D}_{2}=6.17 \times 10^{-19} \mathrm{~m}^{2} / \mathrm{s}$. The comparison between the model and experimental data is shown in Figure 10 ( $\mathrm{M}$ had to be multiplied by 100 to become a percentage release). The maximum deviation between the model and experiment was $1 \%$, which is quite acceptable given the experimental uncertainty. However, the release data showed that there was a small but detectable erosion process (of the order of $1 \%$ per 30 days). This erosion process should be included in the model if even smaller deviations from the data were pursued or predictions for time larger than 50 days were required.

The diblock copolymer TEHA-b-mPEG exhibited the same exact behavior with TEHA-b-PCL. The same Equation (5) was used to fit the data with the corresponding comparison shown in 
Figure 10. The fractions $\mathrm{M}_{1}=0.89$ and $\mathrm{M}_{2}=0.08$ of the drug were diffused with diffusion coefficients $\mathrm{D}_{1}=2.1 \times 10^{-17} \mathrm{~m}^{2} / \mathrm{s}$ and $\mathrm{D}_{2}=4.9 \times 10^{-19} \mathrm{~m}^{2} / \mathrm{s}$, respectively. The diffusion coefficients were comparable to those of TEHA-b-PCL. The remaining (not diffusing) 3\% of the drug was released through erosion with a rate of $1 \%$ per 50 days.

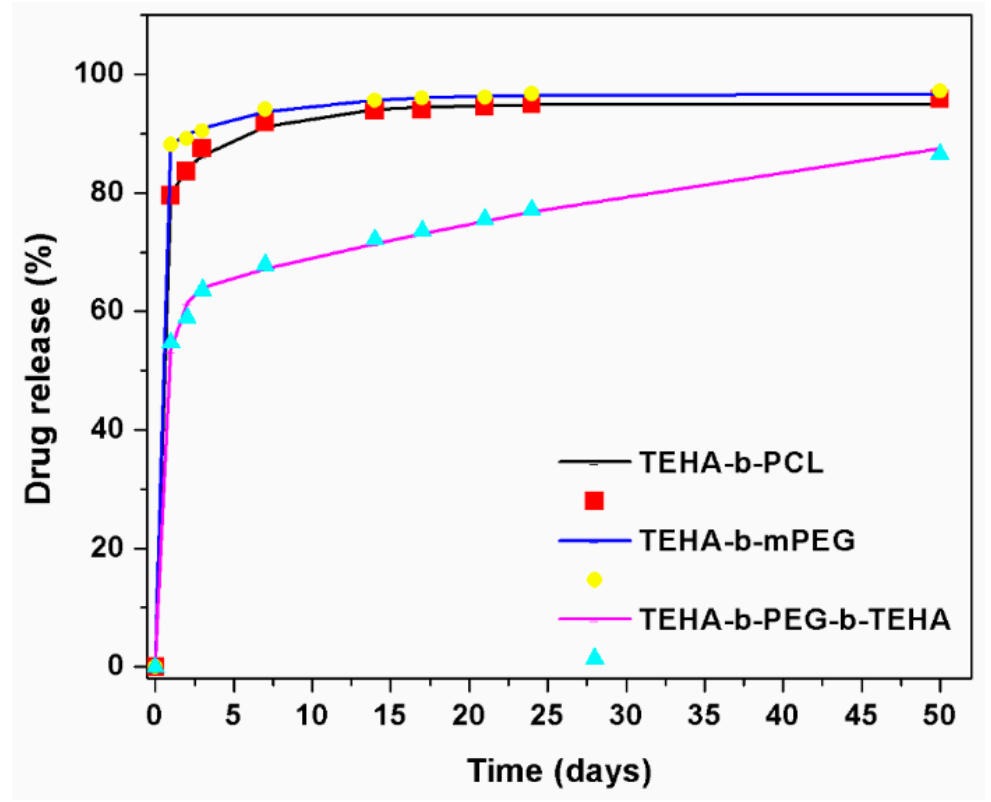

Figure 10. Comparison between model and experimental data of NLX release.

The release data for the triblock copolymer TEHA-b-PEG-b-TEHA shows that there was a large contribution from erosion. The form of the release curve suggests that there was a fraction of the drug release by diffusion alone and another fraction released by erosion alone (no diffusing). The diffusion process ceased before the erosion substantially reduced the size of the particle such that the two release mechanisms could be assumed to act independently. The polymer erosion occurred with a constant rate, let us denote it k (units: length/time) [44]. For a slab geometry, this corresponds to a constant release rate (zero order kinetics). In the case of spherical geometry with a large erosion extent, the situation was somewhat different. The radius of the particle at time $t$ will be $R_{1}=R-k t$ which means that the fraction of non-diffused drug remaining in the particle in this time will be $(\mathrm{R}-\mathrm{kt})^{3} / \mathrm{R}^{3}$. Taking into account the above arguments, the following model equation results for this copolymer:

$$
\mathrm{M}=\mathrm{M}_{1}\left(1-\frac{6}{\pi^{2}} \sum_{\mathrm{i}=1}^{\infty} \frac{1}{\mathrm{i}^{2}} \exp \left(-\mathrm{Di}^{2} \pi^{2} \mathrm{t} / \mathrm{R}^{2}\right)\right)+\left(1-\mathrm{M}_{1}\right)\left(1-(1-\mathrm{kt} / \mathrm{R})^{3}\right)
$$

where $M_{1}$ is the fraction of the drug undergoing diffusion. The rest of the drug (fraction $1-M_{1}$ ) is non-diffusing and it is released during particle erosion. The comparison between model and experimental data is shown in Figure 10. The fitting parameters were (diffusing drug fraction) $\mathrm{M}_{1}=0.625$, (diffusion coefficient) $\mathrm{D}=0.63 \times 10^{-17} \mathrm{~m}^{2} / \mathrm{s}$, and (erosion rate) $\mathrm{k} / \mathrm{R}=0.006 \mathrm{day}^{-1}$. One could unify the observed behavior for all three copolymers saying that there were two modes of diffusion plus erosion release mechanisms. The erosion rate was actually zero for the first two copolymers and the second mode diffusion coefficient was zero for the third copolymer.

\section{Conclusions}

In conclusion, this study confirmed that the castor oil derived copolymers: TEHA-b-PCL, TEHA-b-mPEG, and TEHA-b-PEG-b-TEHA, which could be obtained using a one-pot synthetic procedure involving TEHA, $\varepsilon-\mathrm{CL}, \mathrm{mPEG}$, and PEG, could be efficiently used for the preparation of amphiphilc block copolymer microspheres. The results of the study suggest that several factors, 
such as Mw and composition of the amphiphilic copolymers, significantly affect the morphological, physicochemical, and pharmaceutical characteristics of the resulting NLX-loaded microspheres, which were prepared with a desirable size of 5-10 $\mu \mathrm{m}$ and different entrapment efficiencies, which varied from $7.6 \pm 0.9 \%$ to $25.9 \pm 1.4 \%$. All NLX-loaded microspheres showed an initial burst effect to provide the loading dose of the drug, followed by sustained release for 50 days, suggesting that these delivery systems can be potential carriers for long-acting controlled drug delivery. Furthermore, analysis of release kinetics data shows that the release mechanism was multiple mode Fickian diffusion for TEHA-b-mPEG and TEHA-b-PCL NLX-loaded microspheres. On the contrary, polymer erosion was comparable with the diffusion contribution for the release kinetics for microspheres prepared using the TEHA-b-PEG-b-TEHA copolymer.

Author Contributions: M.N. Investigation, Formal Analysis and Draft Preparation, E.S., K.-V.A. and S.N. Methodology, Formal Analysis and Validation, A.A. Writing-Review \& Editing, K.M. Performed the Release Data Modelling, D.B. Supervision and Writing-Original Draft Preparation.

Conflicts of Interest: The authors declare no conflict of interest.

\section{References}

1. Bader, H.; Ringsdorf, H.; Schmidt, B. Watersoluble polymers in medicine. Die Angew. Makromol. Chem. 1984, 123, 457-485. [CrossRef]

2. Cho, H.K.; Cheong, I.W.; Lee, J.M.; Kim, J.H. Polymeric nanoparticles, micelles and polymersomes from amphiphilic block copolymer. Korean J. Chem. Eng. 2010, 27, 731-740. [CrossRef]

3. Hu, X.; Jing, X. Biodegradable amphiphilic polymer-drug conjugate micelles. Expert Opin. Drug Deliv. 2009, 6, 1079-1090. [CrossRef] [PubMed]

4. Helstrom, A.W.; Blow, F.C.; Slaymaker, V.; Kranzler, H.R.; Leong, S.; Oslin, D. Reductions in alcohol craving following naltrexone treatment for heavy drinking. Alcohol. Alcohol. 2016, 51, 562-566. [CrossRef] [PubMed]

5. Callahan, E.J.; Rawson, R.A.; McCleave, B.; Arias, R.; Glazer, M.; Liberman, R.P. The Treatment of Heroin Addiction: Naltrexone Alone and with Behavior Therapy. Int. J. Addict. 1980, 15, 795-807. [CrossRef] [PubMed]

6. Hulse, G.K. Improving clinical outcomes for naltrexone as a management of problem alcohol use. Br. J. Clin. Pharmacol. 2013, 76, 632-641. [CrossRef] [PubMed]

7. Krupitsky, E.M.; Blokhina, E.A. Long-acting depot formulations of naltrexone for heroin dependence: A review. Curr. Opin. Psychiatry 2010, 23, 210-214. [CrossRef] [PubMed]

8. Goonoo, N.; Bhaw-Luximon, A.; Ujoodha, R.; Jhugroo, A.; Hulse, G.K.; Jhurry, D. Naltrexone: A review of existing sustained drug delivery systems and emerging nano-based systems. J. Control. Release 2014, 183, 154-166. [CrossRef] [PubMed]

9. Comer, S.D.; Sullivan, M.A.; Yu, E.; Rothenberg, J.L.; Kleber, H.D.; Kampman, K.; Dackis, C.; O’Brien, C.P. Injectable, Sustained-Release Naltrexone for the Treatment of Opioid Dependence: A Randomized, Placebo-Controlled Trial. Arch. Gen. Psychiatry 2006, 63, 210-218. [CrossRef] [PubMed]

10. Hulse, G.K.; Stalenberg, V.; McCallum, D.; Smit, W.; O’Neil, G.; Morris, N.; Tait, R.J. Histological changes over time around the site of sustained release naltrexone-poly(DL-lactide) implants in humans. J. Control. Release 2005, 108, 43-55. [CrossRef] [PubMed]

11. Volpicelli, J.R.; Fenton, M. Sustained-release naltrexone formulations for the treatment of alcohol and opioid dependence. Future Neurol. 2006, 1, 389-398. [CrossRef]

12. Akala, E.O.; Wiriyacoonkasem, P.; Pan, G. Studies on in vitro availability, degradation, and thermal properties of naltrexone-loaded biodegradable microspheres. Drug Dev. Ind. Pharm. 2011, 37, 673-684. [CrossRef] [PubMed]

13. Salehi, R.; Nowruzi, K.; Salehi, S.; Khandaghi, A.A.; Davaran, S.; Entezami, A.A. Smart poly ( $N$-isopropylacrylamide)-block-poly (L-Lactide) nanoparticles for prolonged release of naltrexone. Int. J. Polym. Mater. Polym. Biomater. 2013, 62, 686-694. [CrossRef]

14. Pagar, K.P.; Vavia, P.R. Naltrexone-loaded poly[La-(Glc-Leu)] polymeric microspheres for the treatment of alcohol dependence: In vitro characterization and in vivo biocompatibility assessment. Pharm. Dev. Technol. 2014, 19, 385-394. [CrossRef] [PubMed] 
15. Lu, Y.; Park, K. Polymeric micelles and alternative nanonized delivery vehicles for poorly soluble drugs. Int. J. Pharm. 2013, 453, 198-214. [CrossRef] [PubMed]

16. Vassiliou, A.A.; Papadimitriou, S.A.; Bikiaris, D.N.; Mattheolabakis, G.; Avgoustakis, K. Facile synthesis of polyester-PEG triblock copolymers and preparation of amphiphilic nanoparticles as drug carriers. J. Control. Release 2010, 148, 388-395. [CrossRef] [PubMed]

17. Nerantzaki, M.; Adam, K.V.; Koliakou, I.; Skoufa, E.; Avgeropoulos, A.; Papageorgiou, G.Z.; Bikiaris, D. Novel Castor Oil-Derived Block Copolymers as Promising Candidates for Biological Applications: Biorelevant and Biocompatible. Macromol. Chem. Phys. 2017, 218, 1-13. [CrossRef]

18. Beyazkilic, Z.; Lligadas, G.; Ronda, J.C.; Galià, M.; Cádiz, V. Fully biobased triblock copolyesters from l-lactide and sulfur-containing castor oil derivatives: Preparation, oxidation and characterization. Polymer 2015, 68, 101-110. [CrossRef]

19. Türünç, O.; Firdaus, M.; Kleina, G.; Meier, M.A.R. Fatty acid derived renewable polyamides via thiol-ene additions. Green Chem. 2012, 14, 2577-2583. [CrossRef]

20. Kim, S.Y.; Ha, J.C.; Lee, Y.M. Poly(ethylene oxide)-poly(propylene oxide)-poly(ethylene oxide)/ poly(epsilon-caprolactone) (PCL) amphiphilic block copolymeric nanospheres. II. Thermo-responsive drug release behaviors. J. Control. Release 2000, 65, 345-358. [CrossRef]

21. Wang, J.; Yao, K.; Wang, C.; Tang, C.; Jiang, X. Synthesis and drug delivery of novel amphiphilic block copolymers containing hydrophobic dehydroabietic moiety. J. Mater. Chem. B 2013, 1, 2324-2332. [CrossRef]

22. Desroches, M.; Caillol, S.; Lapinte, V.; Auvergne, R.; Boutevin, B. Synthesis of biobased polyols by thiol-ene coupling from vegetable oils. Macromolecules 2011, 44, 2489-2500. [CrossRef]

23. Danafar, H. MPEG-PCL copolymeric nanoparticles in drug delivery systems. Cogent Med. 2016, 3, 1142411. [CrossRef]

24. Callari, M.; De Souza, P.L.; Rawal, A. The Effect of Drug Loading on Micelle Properties: Solid-State NMR as a Tool to Gain Structural Insight. Angew. Chem. In.t Ed. 2017, 56, 8441-8445. [CrossRef] [PubMed]

25. Gaucher, G.; Dufresne, M.H.; Sant, V.P.; Kang, N.; Maysinger, D.; Leroux, J.C. Block copolymer micelles: Preparation, characterization and application in drug delivery. J. Control. Release 2005, 109, 169-188. [CrossRef] [PubMed]

26. Riess, G. Micellization of block copolymers. Prog. Polym. Sci. 2003, 28, 1107-1170. [CrossRef]

27. Tan, Q.; Chu, Y.; Bie, M.; Wang, Z.; Xu, X. Preparation and Investigation of Amphiphilic Block Copolymers/Fullerene Nanocomposites as Nanocarriers for Hydrophobic Drug. Materials 2017, 10, 192. [CrossRef] [PubMed]

28. Rösler, A.; Vandermeulen, G.W.; Klok, H.A. Advanced drug delivery devices via self-assembly of amphiphilic block copolymers. Adv. Drug Deliv. Rev. 2001, 53, 95-108. [CrossRef]

29. Saralidze, K.; Koole, L.H.; Knetsch, M.L.W. Polymeric microspheres for medical applications. Materials 2010, 3, 537-564. [CrossRef]

30. Kyu, S.; Dukjoon, C. Drug-releasing behavior of MPEG/PLA block copolymer micelles and solid particles controlled by component block length. J. Appl. Polym. Sci. 2002, 83, 435-445. [CrossRef]

31. Li, G.; Li, D.; Niu, Y.; He, T.; Chen, K.C.; Xu, K. Alternating block polyurethanes based on PCL and PEG as potential nerve regeneration materials. J. Biomed. Mater. Res. 2014, 102, 685-697. [CrossRef] [PubMed]

32. Nidhi, K.; Indrajeet, S.; Khushboo, M.; Gauri, K.; Sen, D.J. Hydrotropy: A promising tool for solubility enhancement: A review. Int. J. Drug Dev. Res. 2011, 3, 26-33.

33. Chen, C.; Xie, X.; Li, Y.; Zhou, C.; Song, Y.; Yan, Z.; Yan, X. Influence of different polymers on crystallization tendency and dissolution behavior of cilnidipine in solid dispersions. Drug Dev. Ind. Pharm. 2014, 40, 441-451. [CrossRef] [PubMed]

34. Karavelidis, V.; Karavas, E.; Giliopoulos, D.; Papadimitriou, S.; Bikiaris, D. Evaluating the effects of crystallinity in new biocompatible polyester nanocarriers on drug release behavior. Int. J. Nanomed. 2011, 6, 3021-3032. [CrossRef]

35. Ahmad, Z.; Shah, A.; Siddiq, M.; Kraatz, H.B. Polymeric micelles as drug delivery vehicles. RSC Adv. 2014, 4, 17028-17038. [CrossRef]

36. Ke, X.; Ng, V.W.L.; Ono, R.J.; Chan, J.M.W.; Krishnamurthy, S.; Wang, Y.; Hedrick, J.L.; Yang, Y.Y. Role of non-covalent and covalent interactions in cargo loading capacity and stability of polymeric micelles. J. Control. Release 2014, 193, 9-26. [CrossRef] [PubMed] 
37. Miller, T.; Van Colen, G.; Sander, B.; Golas, M.M.; Uezguen, S.; Weigandt, M.; Goepferich, A. Drug loading of polymeric micelles. Pharm. Res. 2013, 30, 584-595. [CrossRef] [PubMed]

38. Karavelidis, V.; Bikiaris, D.; Avgoustakis, K. New thermosensitive nanoparticles prepared by biocompatible pegylated aliphatic polyester block copolymers for local cancer treatment. J. Pharm. Pharmacol. 2015, 67, 215-230. [CrossRef] [PubMed]

39. Karavelidis, V.; Giliopoulos, D.; Karavas, E.; Bikiaris, D. Nanoencapsulation of a water soluble drug in biocompatible polyesters. Effect of polyesters melting point and glass transition temperature on drug release behavior. Eur. J. Pharm. Sci. 2010, 41, 636-643. [CrossRef] [PubMed]

40. Casalini, T.; Rossi, F.; Lazzari, S.; Perale, G.; Masi, M. Mathematical Modeling of PLGA Microparticles: From Polymer Degradation to Drug Release. Mol. Pharm. 2014, 11, 4036-4048. [CrossRef] [PubMed]

41. Korsmeyer, R.W.; Gurny, R.; Doelker, E.; Buri, P.; Peppas, N.A. Mechanisms of solute release from porous hydrophilic polymers. Int. J. Pharm. 1983, 15, 25-35. [CrossRef]

42. Crank, J. The Mathematics of Diffusion, 2nd ed.; Clarendon Press Oxford University Press: Oxford, UK, 1976; ISBN 10-0198534116.

43. Tien, C. Adsorption Calculations and Modeling; Series in Chemical Engineering; Butterworth Heinemann: Boston, MA, USA, 1994; ISBN 9780750691215.

44. Parker, A.; Vigouroux, F.; Reed, W.F. Dissolution kinetics of polymer powders. Fluid Mech. Transp. Phenom. 1999, 218, 1290-1299. [CrossRef]

(C) 2018 by the authors. Licensee MDPI, Basel, Switzerland. This article is an open access article distributed under the terms and conditions of the Creative Commons Attribution (CC BY) license (http:/ / creativecommons.org/licenses/by/4.0/). 